University of Nebraska - Lincoln

DigitalCommons@University of Nebraska - Lincoln

2012

\title{
Isothermal entropy changes in nanocomposite $\mathrm{Co:Ni} 67 \mathrm{Cu}_{33}$
}

\author{
Steven A. Michalski \\ University of Nebraska-Lincoln, smichalski2@unl.edu \\ Ralph Skomski \\ University of Nebraska-Lincoln, rskomski2@unl.edu \\ Xingzhong Li \\ University of Nebraska-Lincoln, xli2@unl.edu \\ Damien Le Roy \\ University of Nebraska-Lincoln, damien.le-roy@grenoble.cnrs.fr \\ Tathagata Mukherjee \\ University of Nebraska-Lincoln, tatha.muk@gmail.com \\ See next page for additional authors
}

Follow this and additional works at: https://digitalcommons.unl.edu/physicssellmyer

Part of the Physics Commons

Michalski, Steven A.; Skomski, Ralph; Li, Xingzhong; Le Roy, Damien; Mukherjee, Tathagata; Binek, Christian; and Sellmyer, David J., "Isothermal entropy changes in nanocomposite Co:Ni67Cu33" (2012).

David Sellmyer Publications. 226.

https://digitalcommons.unl.edu/physicssellmyer/226

This Article is brought to you for free and open access by the Research Papers in Physics and Astronomy at DigitalCommons@University of Nebraska - Lincoln. It has been accepted for inclusion in David Sellmyer Publications by an authorized administrator of DigitalCommons@University of Nebraska - Lincoln. 


\section{Authors}

Steven A. Michalski, Ralph Skomski, Xingzhong Li, Damien Le Roy, Tathagata Mukherjee, Christian Binek, and David J. Sellmyer 


\title{
Isothermal entropy changes in nanocomposite $\mathrm{Co:} \mathrm{Ni}_{67} \mathrm{Cu}_{33}$
}

\author{
S. Michalski, ${ }^{\text {a) }}$ R. Skomski, X.-Zh. Li, D. Le Roy, T. Mukherjee, Ch. Binek, and D. J. Sellmyer \\ Department of Physics and Astronomy and Nebraska Center for Materials and Nanoscience, \\ University of Nebraska, Lincoln, Nebraska 68588, USA
}

(Presented 31 October 2011; received 23 September 2011; accepted 10 November 2011; published online 6 March 2012)

\begin{abstract}
The temperature-dependent magnetic properties of artificial rare-earth, free-magnetic nanostructures are investigated for magnetic cooling. We consider two-phase nanocomposites, where $2 \mathrm{~nm}$ nanoclusters of cobalt are embedded in a $\mathrm{Ni}_{67} \mathrm{Cu}_{33}$ matrix. Several composite films were produced by cluster deposition. The average Co nanocluster size can be tuned by varying the deposition conditions. Isothermal magnetization curves were measured at various temperatures $150 \mathrm{~K}<\mathrm{T}<340 \mathrm{~K}$ in steps of $10 \mathrm{~K}$. The isothermal entropy changes $\Delta S$ were calculated using the Maxwell relation. The entropy changes measured were, $-\Delta S=0.15 \mathrm{~J} / \mathrm{kg} \cdot \mathrm{K}$ in a field change of $1 \mathrm{~T}$ at $260 \mathrm{~K}$ and $0.72 \mathrm{~J} / \mathrm{kg} \cdot \mathrm{K}$ in a field change of $7 \mathrm{~T}$ at $270 \mathrm{~K}$. (C) 2012 American Institute of Physics. [doi:10.1063/1.3676423]
\end{abstract}

\section{INTRODUCTION}

The search for room temperature magnetic refrigeration based on the magnetocaloric effect (MCE) has intensified in recent years because magnetic refrigeration is an environmentally friendly and energy-efficient technology. ${ }^{1-5}$ Developing an efficient magnetic refrigerator which operates near room temperature requires the discovery of advanced new materials with tailored magnetic and structure properties which can produce a large isothermal entropy change and a large adiabatic temperature change at lower magnetic fields. Currently, the majority of the research has focused on bulk rare-earth alloys that exhibit the giant $\mathrm{MCE}^{1,3,6-10}$ and on newly discovered materials which allow overcoming the magnetic limit. ${ }^{11-13}$ Also, recently, there has been a trend to use nanostructuring to tailor the magnetic properties, such as the anisotropy and exchange, to enhance the MCE of the materials by maximizing the isothermal entropy change in lower magnetic fields, suppressing hysteresis losses, and tuning the operation temperature to the desired range. ${ }^{14-18}$

Researchers traditionally use magnetic phase transitions to enhance the isothermal entropy change and tune the operating temperature of MCE material, since, near transition temperatures, the effect of the applied magnetic field is increased due to the internal interatomic exchange interactions $J_{\mathrm{ex}}{ }^{1,3}$ First-order transitions can help if the phases involved have different entropies, which can produce large entropy changes. ${ }^{17}$ Second-order transitions can be used if the transition temperature is close to the desired operating temperature and the transitions are sharp enough to yield a significant isothermal entropy change. Our aim is to use magnetic phase transitions, but also to use nanostructuring to enhance the MCE. The idea is to embed magnetic nanoclusters of $N$ atoms into a ferromagnetic matrix with a Curie temperature close to room temperature. The nanoclusters have large "macrospins" $J \sim N$ and the entropy $S$ of the clusters increases logarithmically with $N$, but the heat capacity scales with $N(C \sim N)$; therefore, the clusters cannot be large. ${ }^{16,17}$

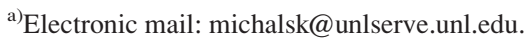

Embedding the nanoclusters into a interacting magnetic matrix effectively increases the quantum number $J$ or the total spin of the composite material, which should enhance the isothermal entropy change. ${ }^{17}$

This paper focuses on nanocomposites where Co nanoclusters, having an average cluster size of $2.0 \mathrm{~nm}$, are embedded in a disordered-alloy matrix of $\mathrm{Ni}-\mathrm{Cu}$ with compositions close to $\mathrm{Ni}_{67} \mathrm{Cu}_{33}$. Ni-Cu was chosen for the matrix, because it is rare-earth free, ready available, and because its Curie temperature can be tuned by varying the copper concentration. The Curie temperature $T_{\mathrm{c}}$ of bulk $\mathrm{Ni}_{70} \mathrm{Cu}_{30}$ is $300 \mathrm{~K}$, which decreases with decreasing $\mathrm{Ni}$ concentration at a rate of about $11.2 \mathrm{~K}$ per at. $\% \mathrm{Ni}^{19}{ }^{19}$ The composition was chosen since its Curie temperature would be close to room temperature.

\section{EXPERIMETAL METHODS}

A homemade cluster-deposition system ${ }^{20}$ was used to produce the $\mathrm{Co}$ nanoclusters and deposit them into the $\mathrm{Ni}-\mathrm{Cu}$ matrix. The system combines a dc magnetron sputtering gun with a high-purity Co target contained in a gas-aggregation chamber held at liquid nitrogen temperatures. Argon is used as the process gas with pressures in the range 100-140 mTorr; Co atoms are sputtered into the gas-aggregation chamber, where they are condensed by the cooled inert gas-forming clusters. The cluster size can be controlled by varying sputtering power, Ar pressure, and gas-aggregation chamber length. After cluster formation, a differential pressure pushes the nanoclusters into a deposition chamber onto a substrate. The deposition chamber also contains two sputtering guns for different matrix materials. The Ni-Cu matrix was sputtered from a composite target produced by embedding $99.998 \%$ pure copper cylinders into a $99.95 \%$ pure nickel target. All samples were deposited onto Si (100) substrates.

The cluster-embedded samples are produced in a manner similar to deposition of multilayers. A matrix layer of thickness $\mathrm{x} \mathrm{nm}$ is deposited first, then a y-nm-thick layer of the nanoclusters is deposited and the multilayering is repeated until a desired total thickness is reached. Two reference samples were fabricated; a $\mathrm{Ni}-\mathrm{Cu}$ sample of thickness 
of $89.4 \mathrm{~nm}$ and a sample with the Co nanoclusters dispersed in a nonmagnetic $\mathrm{SiO}_{2}$ matrix with the structure $\left(\left[\mathrm{SiO}_{2}\right.\right.$ $3.1 \mathrm{~nm} / \mathrm{Co} 0.4 \mathrm{~nm}]_{15} / \mathrm{SiO}_{2} 3.1 \mathrm{~nm}$ ). Next, we produced a Co nanoclusters-embedded sample with large volume fraction $20 \%$ of $\mathrm{Co}$ nanoclusters and with a structure $\left(\left[\mathrm{Ni}_{67} \mathrm{Cu}_{33}\right.\right.$ $3.1 \mathrm{~nm} / \mathrm{Co} 0.8 \mathrm{~nm}]_{10} / \mathrm{Ni}_{67} \mathrm{Cu}_{33} 3.1 \mathrm{~nm} \backslash \mathrm{SiO}_{2} 16 \mathrm{~nm}$ ). During a different deposition, two more samples were produced with the structure $\left(\left[\mathrm{Ni}_{67} \mathrm{Cu}_{33} 3.9 \mathrm{~nm} / \mathrm{Co} \text { y nm }\right]_{10} / \mathrm{Ni}_{67} \mathrm{Cu}_{33} 3.9\right.$ $\mathrm{nm} \backslash \mathrm{SiO}_{2} 18 \mathrm{~nm}$ ) with $\mathrm{y}=0.1$ and $0.3 \mathrm{~nm}$, which correspond to Co volume fractions of 2 and $6 \%$.

The atomic compositions of the $\mathrm{Ni}-\mathrm{Cu}$ films were measured using an $\mathrm{x}$ ray energy-dispersive spectrometer in a scanning electron microscope (SEM). Several spots on the film were measured and averaged to obtain the composition $\mathrm{Ni}_{67} \mathrm{Cu}_{33}$ with an error of $1 \%$. Transmission electron microscopy (TEM) was used to measure the size and distribution of nanoclusters. Structure properties were measured by $\mathrm{x}$ ray and electron diffraction. The magnetic properties were measured using a Quantum Design superconducting quantum interference device (SQUID) with a maximum magnetic field of $7 \mathrm{~T}$ and a maximum temperature of $400 \mathrm{~K}$.

\section{RESULTS AND DISCUSSION}

Figure 1 shows a TEM image of the Co nanoclusters after deposition onto a TEM Cu grid with a $1.5-\mathrm{nm}$ overcoat of $\mathrm{SiO}_{2}$. The inset shows the size distribution of the particles with a log-normal fit; the average diameter is $1.95 \mathrm{~nm}$ and the standard deviation $\sigma / D$ is 0.14 . X ray and electron diffraction show that the as-deposited Co nanoclusters are in a FCC structure. SQUID measurements show that, for sample $\left(\left[\mathrm{SiO}_{2} 3.1 \mathrm{~nm} / \mathrm{Co} 0.4 \mathrm{~nm}\right]_{15} / \mathrm{SiO}_{2} 3.1 \mathrm{~nm}\right)$, the Co nanoclusters are ferromagnetic, with a coercivity of $15 \mathrm{mT}$ at $300 \mathrm{~K}$ and a coercivity of $58 \mathrm{mT}$ at $10 \mathrm{~K}$. The intrinsic anisotropy of the FCC Co nanoclusters is certainly not high enough to stabilize the magnetization at $300 \mathrm{~K} .{ }^{21}$ The most likely cause of the observed hysteresis at $300 \mathrm{~K}$ is from inter-particle dipole or exchange interactions between the nanoclusters.

The $\mathrm{M}(\mathrm{H})$ isotherms of the 89.4-nm-thick $\mathrm{Ni}_{67} \mathrm{Cu}_{33}$ sample in fields $0 \leq \mu_{0} H \leq 7 \mathrm{~T}$ were measured for $T=150-330 \mathrm{~K}$ in steps of $10 \mathrm{~K}$. All isothermals were measured using the loop process, ${ }^{22}$ where all isotherms have been

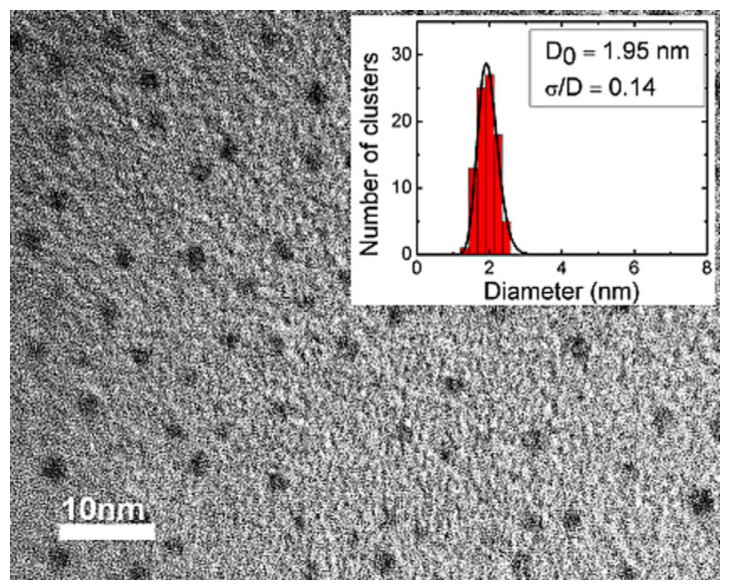

FIG. 1. (Color online) Co nanoclusters: TEM micrograph. The inset shows the size distribution and log-normal fit of the size distribution. reinitialized by zero field cooling from $360 \mathrm{~K}$. A sampling of the isotherms is shown in Fig. 2(a). The isothermal entropy $\Delta S$ was calculated using the isotherm data and the Maxwell relation,

$$
\Delta S=\mu_{0} \int_{H_{i}}^{H_{f}}\left(\frac{\partial m}{\partial T}\right)_{H} d H
$$

where $m$ is the magnetic moment of the sample. Figure 2(b) shows the $-\Delta S$, as a function of temperature for the $89.4-\mathrm{nm}$ $\mathrm{Ni}_{67} \mathrm{Cu}_{33}$ sample in magnetic field, changes up to $7 \mathrm{~T}$. The mass of the Ni-Cu layer was estimated using the volume deposited and assuming a density of $8.92 \mathrm{~g} / \mathrm{cm}^{3}$. The Ni-Cu matrix produces a maximum entropy change of $-\Delta S \sim 0.59$ (J/ $(\mathrm{kg} \mathrm{K})$, in a field change of $7 \mathrm{~T}$ at around $240 \mathrm{~K}$, which is near the Curie temperature of the $\mathrm{Ni}-\mathrm{Cu}$ alloy.

The two samples with a low volume fraction of Co $\left(\left[\mathrm{Ni}_{67} \mathrm{Cu}_{33} 3.9 \mathrm{~nm} / \text { Co y nm }\right]_{10} / \mathrm{Ni}_{67} \mathrm{Cu}_{33} 3.9 \mathrm{~nm} \mathrm{SiO}_{2} 18 \mathrm{~nm}\right)$ with $\mathrm{y}=0.1$ and $0.3 \mathrm{~nm}$ show similar behavior for the isothermal entropy change. The $\mathrm{M}(\mathrm{H})$ isotherms of both samples in fields $0 \leq \mu_{0} H \leq 7 \mathrm{~T}$ were measured for $T=160-340 \mathrm{~K}$ in steps of $10 \mathrm{~K}$. Figure 3(a) shows a typical set of isotherms measured for the sample $\left(\left[\mathrm{Ni}_{67} \mathrm{Cu}_{33} 3.9 \mathrm{~nm} / \mathrm{Co} \quad 0.3 \mathrm{~nm}\right]_{10} /\right.$ $\mathrm{Ni}_{67} \mathrm{Cu}_{33} 3.9 \mathrm{~nm} \backslash \mathrm{SiO}_{2} 18 \mathrm{~nm}$ ). Figure 3(b) shows the isothermal entropy change $-\Delta S$ for the same sample. The isothermal entropy change is $-\Delta S=0.15 \mathrm{~J} /(\mathrm{kg} \mathrm{K})$ for $\mu_{0} \Delta H=1 \mathrm{~T}$ at $260 \mathrm{~K}$
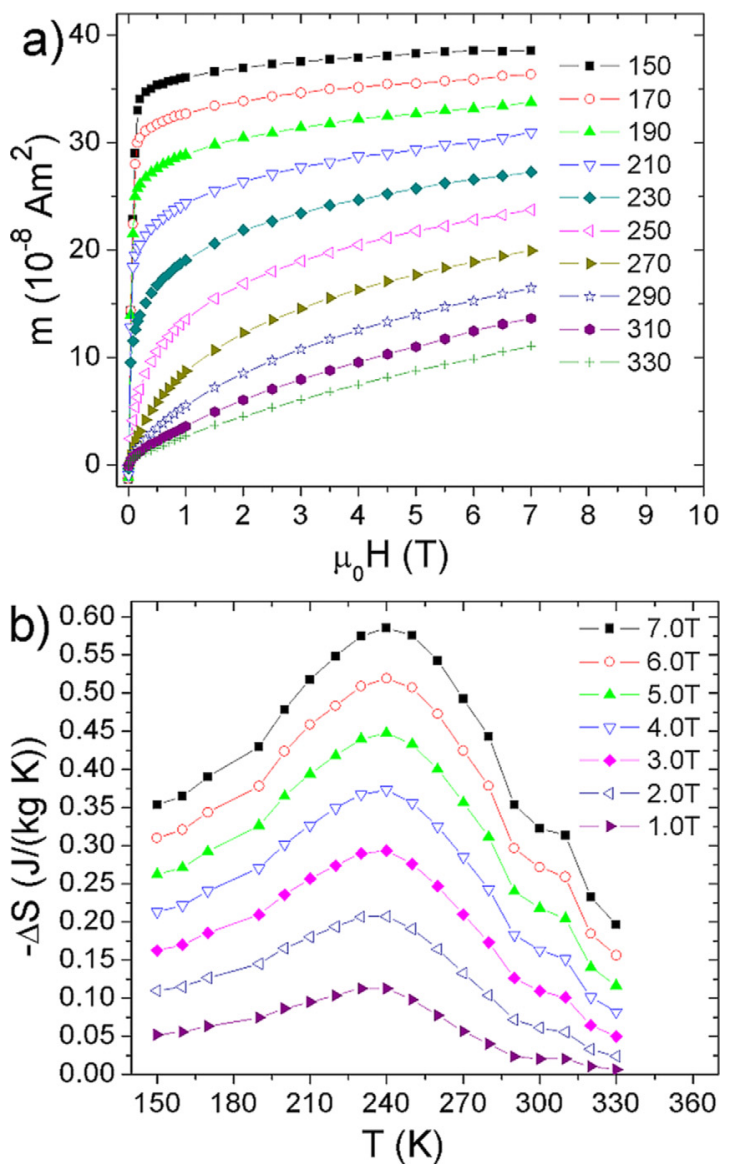

FIG. 2. (Color online) Magnetic and entropic properties of the sample $\mathrm{Ni}_{67} \mathrm{Cu}_{33} 89.4 \mathrm{~nm}$. (a) Isotherms at various temperatures. (b) Isothermal entropy change $-\Delta S$ as a function of temperature, as calculated from the Maxwell relation for various $\mu_{0} \Delta H$. 

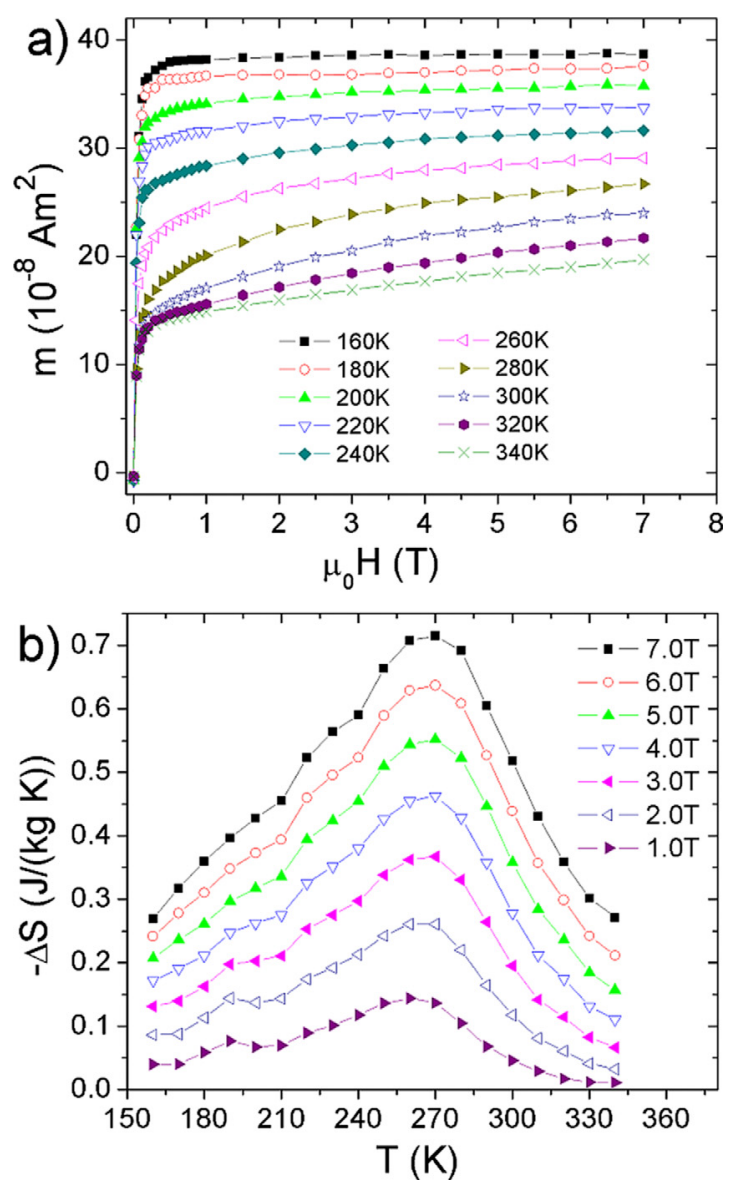

FIG. 3. (Color online) Magnetic and entropic properties of the sample $\left(\left[\mathrm{Ni}_{67} \mathrm{Cu}_{33} 3.9 \mathrm{~nm} / \mathrm{Co} 0.3 \mathrm{~nm}\right]_{10} / \mathrm{Ni}_{67} \mathrm{Cu}_{33} 3.9 \mathrm{~nm}\right)$ : (a) Isotherms at various temperatures and (b) isothermal entropy change $-\Delta S$ as a function of temperature, as calculated from the Maxwell relation for various field changes.

and reaches a maximum of $0.72 \mathrm{~J} /(\mathrm{kg} \mathrm{K})$ for $\mu_{0} \Delta H=7 \mathrm{~T}$ at $270 \mathrm{~K}$. The entropy change for the sample with $\mathrm{y}=0.1 \mathrm{~nm}$ is $-\Delta S=0.15 \mathrm{~J} /(\mathrm{kg} \mathrm{K})$ for $\mu_{0} \Delta H=1 \mathrm{~T}$ at $260 \mathrm{~K}$ and reaches a maximum of $0.69 \mathrm{~J} /(\mathrm{kg} \mathrm{K})$ for $\mu_{0} \Delta H=7 \mathrm{~T}$ at $270 \mathrm{~K}$. The sam-

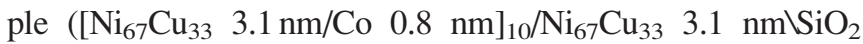
$16 \mathrm{~nm}$ ) with a large volume fraction of Co shows a different behavior; the entropy peak becomes smaller and shifts to a lower temperature $-\Delta S=0.03 \mathrm{~J} /(\mathrm{kg} \mathrm{K})$ for $\mu_{0} \Delta H=1 \mathrm{~T}$ and reaches a maximum of $0.28 \mathrm{~J} /(\mathrm{kg} \mathrm{K})$ for $\mu_{0} \Delta H=7 \mathrm{~T}$ at $220 \mathrm{~K}$. Even though the effect of embedding the Co nanoclusters on the isothermal entropy change is modest, we still see a $20 \%$ increase in the entropy change when low amounts of nanoclusters are embedded. For high volume fractions of the Co clusters, the isothermal entropy change decreases, which is probably caused by the Co nanoclusters percolating in the sample shifting the Curie temperature. Zero field cooled (ZFC) and field cooled (FC) data support this explanation, as, for the low volume fraction of Co samples, ZFC-FC data show a sharp transition around the Curie temperature of the $\mathrm{Ni}-\mathrm{Cu}$ matrix, but for the larger volume fraction, the transition becomes broader and shifts to a higher temperature.

\section{CONCLUSION}

In summary, we have presented preliminary data on nanocomposite $\mathrm{Co}: \mathrm{Ni}_{67} \mathrm{Cu}_{33}$ to investigate the effect of nanostructuring on the isothermal entropy change. In the present system, the entropy change is $0.72 \mathrm{~J} /(\mathrm{kg} \mathrm{K})$, but we do see a $20 \%$ enhancement of the entropy change for low volume fractions of Co nanoclusters, due to the coupling between the nanoclusters and the matrix. Further experimental research is underway to find ways to maximize the isothermal entropy change and to fully exploit the potential of nanostructuring.

\section{ACKNOWLEDGMENTS}

This work is supported by the Nebraska Research Initiative (S.M. and R.S.), Army Research Office under award No. W911-NF-09-2-0039 (D.L.R., X.Z.L., and D.J.S.), NSF Career DMR-0547887 (T.M. and Ch.B.), and NCMN [Central Facility Support].

${ }^{1}$ E. Brück, O. Tegus, D. T. C. Thanh, and K. H. J. Buschow, J. Magn. Magn. Mater. 310, 2793 (2007).

${ }^{2}$ C. Zimm, A. Jastrab, A. Sternberg, V. K. Pecharsky, K. A. Gschneidner, Jr., M. Osborne, and I. Anderson, in Advances in Cryogenic Engineering, edited by Peter Kittel (Plenum Press, New York, 1998), Vol. 43, Part B, p. 1759.

${ }^{3}$ K. A. Gschneidner, Jr., V. K. Pecharsky, and A. O. Tsokol, Rep. Prog. Phys. 68, 1479 (2005).

${ }^{4}$ R. D. McMichael, R. D. Shull, L. J. Swartzendruber, and L. H. Bennett, J. Magn. Magn. Mater. 111, 29 (1992).

${ }^{5}$ V. K. Pecharsky and K. A. Gschneidner, Jr., J. Magn. Magn. Mater. 200, 44 (1999).

${ }^{6}$ S. B. Roy, P. Chaddah, V. K. Pecharsky, and K. A. Gschneidner, Jr., Acta Mater. 56, 5895 (2008).

${ }^{7}$ C. S. Aleves, S. Gama, A. de A. Coelho, E. J. R. Plaza, A. M. G. Carvalho, L. P. Cardoso, and A. C. Persiano, Mater. Res. 7, 535 (2004).

${ }^{8}$ Q. Luo and W. H. Wang, J. Alloys Compd. 495, 209 (2010).

${ }^{9}$ A. Campos, D. L. Rocco, A. Magnus, G. Carvalho, L. Caron, A. A. Coelho, S. Gama, L. M. D. Silva, F. C. G. Gandra, A. O. D. Santos, L. P. Cardoso, P. J. von Ranke, and N. A. de Oliveira, Nature Mater. 5, 802 (2006).

${ }^{10}$ S. Fujieda, A. Fujita, and K. Fukamichi, Appl. Phys. Lett. 81, 1276 (2002).

${ }^{11}$ J. D. Zou, H. Wada, B. G. Shen, J. R. Sun, and W. Li, Europhys. Lett. 81, 47002 (2008).

${ }^{12}$ J. Lyubina, O. Gutfleisch, M. D. Kuz'min, and M. Richter, J. Magn. Magn. Mater. 321, 3571 (2009).

${ }^{13}$ T. Mukherjee, S. Michalski, R. Skomski, D. J. Sellmyer, and Ch. Binek, Phys. Rev. B 83, 214413 (2011).

${ }^{14}$ T. Mukherjee, S. Sahoo, R. Skomski, D. J. Sellmyer, and Ch. Binek, Phys. Rev. B 79, 144406 (2009).

${ }^{15}$ S. Thota, Q. Zhang, F. Guillou, U. Lüders, N. Barrier, W. Prellier, A. Wahl, and P. Padhan, Appl. Phys. Lett. 97, 112506 (2010).

${ }^{16}$ R. Skomski, Ch. Binek, T. Mukherjee, S. Sahoo, and D. J. Sellmyer, J. Appl. Phys. 103, 07B329 (2008).

${ }^{17}$ R. Skomski, Ch. Binek, S. Michalski, T. Mukherjee, A. Enders, and D. J. Sellmyer, J. Appl. Phys. 107, 09A922 (2010).

${ }^{18}$ S. Michalski, R. Skomski, T. Mukherjee, X.-Zh. Li, Ch. Binek, and D. J. Sellmyer, J. Appl. Phys. 109, 07A936 (2011).

${ }^{19}$ S. A. Ahern, M. J. C. Martin, and W. Sucksmith, Proc. R. Soc. London, Ser. A 248, 145 (1958).

${ }^{20}$ Y. F. Xu, M. L. Yan, and D. J. Sellmyer, in Advanced Magnetic Nanostructures, edited by D. J. Sellmyer and R. Skomski (Springer, New York, 2006), Chap. 8, p. 207.

${ }^{21}$ D. Le Roy, R. Morel, S. Pouget, A. Brenac, L. Notin, T. Crozes, and W. Wernsdorfer, Phys. Rev. Lett. 107, 057204 (2011).

${ }^{22}$ L. Caron, Z. Q. Ou, T. T. Nguyen, D. T. Cam Thanh, O. Tegus, and E. Brück, J. Magn. Magn. Mater. 321, 3559 (2009). 